\title{
The incidence of distal radius fractures in a Swedish pediatric population - an observational cohort study of 90970 individual fractures
}

Hanna Südow ( $\sim$ hanna.sudow@ki.se )

Karolinska Institute

Cecilia Mellstrand Navarro

Karolinska Institute

\section{Research Article}

Keywords: Pediatric fracture, distal radius fracture, epidemiology, seasonal variations, trends

Posted Date: February 26th, 2021

DOI: https://doi.org/10.21203/rs.3.rs-244249/v1

License: (c) (i) This work is licensed under a Creative Commons Attribution 4.0 International License.

Read Full License 
The incidence of distal radius fractures in a Swedish pediatric population - an observational cohort study of 90970 individual fractures

Hanna Südow*, MD, Cecilia Mellstrand Navarro, MD, PhD

*Corresponding author details:

Hanna Südow

Department of Clinical Science and Education, Södersjukhuset, Karolinska Institutet, Institution: Karolinska Institutet, Department of Orthopedics, Södersjukhuset hospital, Stockholm, Sweden

Address: Sjukhusbacken 10, Södersjukhuset, SE-118 46, Stockholm

E-mail: hanna.sudow@ki.se

Phone: +46(0)86161000

\section{Co-author:}

Cecilia Mellstrand Navarro

Department of Clinical Science and Education, Södersjukhuset, Karolinska Institutet, Department of Hand Surgery, Södersjukhuset hospital, Stockholm, Sweden

E-mail: cecilia.mellstrand-navarro@sll.se

\section{Key words:}

Pediatric fracture, distal radius fracture, epidemiology, seasonal variations, trends 


\section{Abstract}

Background

$40-50 \%$ of all boys and $30-40 \%$ of girls suffer from at least one fracture during childhood. A quarter of these fractures affects the wrist, making it the worst affected part of the body. Children often sustain the injury during play or sport activities. There has been a lifestyle change among European children during the last decades, and there is reason to believe that fracture incidence is changing.

\section{Methods}

For the purpose of this observational cohort study registry data was retrieved from the Swedish National Patient Register for all pediatric patients registered with a distal radius fracture during the period 2005 - 2013. Incidence rates were calculated for each year using data from Statistic Sweden on population size by age and gender.

\section{Results}

90970 distal radius fractures were identified. The mean age at the time of fracture was 10 years. In ages 10-17 the proportion of male patients was significantly larger. Seasonal variations were detected with peak incidences in May and September. A decreasing total fracture incidence was observed during the study period.

\section{Conclusion}

The incidence of distal radius fractures in a population $0-17$ years in Sweden was higher among male than in female patients. The incidence was lower in $2008-2013$ as compared to 2005. Further studies are necessary to reveal if the incidence will continue to decrease. 


\section{Background}

Fractures are common injuries among children. Nearly $40-50 \%$ of all boys and $30-40 \%$ of girls suffer from at least one fracture during childhood ${ }^{1,2}$. Among all pediatric fractures the wrist is the most affected site and represents $25 \%$ of all fractures in children ${ }^{2,3}$. It most commonly occurs when the child is falling on an extended $\operatorname{arm}^{2,4,5}$. Falling while playing in a monkey bar or a trampoline are two frequently reported trauma mechanisms for younger children while the teenagers tend to sustain fractures during sports ${ }^{6}$. The incidence has been reported to peak during early stages of puberty $^{7-9}$ when the volumetric bone mineral density is relatively low. ${ }^{7}$

The injury is often benign and most of the affected children will recover without any major sequelae $^{10}$. A majority of cases are treated non-surgically with a bandage or a forearm cast and sometimes with a cast that immobilizes the elbow, depending on patient age and the character of the fracture ${ }^{10}$. In case of fracture patterns too displaced to be tolerated, closed reduction with or without surgical treatment with percutaneous pinning is recommended ${ }^{11}$. Treatment with open reduction and internal fixation is uncommon in the pediatric population $^{10}$.

There is reason to believe that there has been a lifestyle change among European children during the last decades, due to a continuous introduction of new technical devices to a broad population. The time children and teenagers spent on physical activities has been reported to decline ${ }^{12}$. How these lifestyle changes affect children's health in general, and more specifically distal radius fracture incidence is largely unknown. Publications presenting fracture incidence in pediatric populations have shown an increasing trend for many decades $3,13,14$. A study in a British setting reports data from 2007 - 2014 and showed no change in incidence of distal radius fractures during that period ${ }^{15}$.

Most of the available data regarding radius fracture incidence in children describes what has happened over decades and are limited to small populations or reports from regional findings. Knowledge regarding the fracture development in the new and rapidly developing millennium is spare.

The aim of this nationwide registry study was to investigate the incidence of distal radius fractures in the pediatric population in Sweden during $2005-2013$.

\section{Methods}

This is a descriptive observational cohort study analyzing Swedish nationwide registry data from 2005-2013. The Swedish National Patient Register (NPR) contains data from mandatory registrations of all inpatient care since 1987, and outpatient care since 2001, and is kept by the Swedish National Board of Health and Welfare under the Ministry of Health and Social Affairs. ${ }^{16}$ Diagnoses are registered through the Swedish version of the International statistical classification of diseases and related health problems $10^{\text {th }}$ revision (ICD-10-SE) code system. The coverage of the Swedish NPR is high and data has been reported to be valid ${ }^{17}$.

Data were retrieved for all registrations of distal radius fractures in pediatric patients during the period 2005 through 2013. Patients were identified by the occurrence of the ICD-10-SE 
codes S52.5 fracture to the distal radius or S52.6 fracture to the distal part of radius and ulna. The study population were all individuals 0-17 years at the day of diagnosis.

A fracture event was defined as the first time the diagnosis S52.5 or S52.6 appeared in the register. If the diagnosis code S52.5 or S52.6 reappeared after a period of at least 18 months without any registrations of a distal radius or ulna fracture, it was considered a re-fracture, and counted as a fracture event. Simultaneous bilateral fracture or repetitive fracture within 18 months were counted as only one fracture. All individuals were sorted into four age groups: 06 years, 7-10 years, 11-14 years, 15-17 years.

Data on population size was collected from Statistics Sweden ${ }^{18}$ including numbers of inhabitants in one-year age groups broken down by sex as for November $1^{\text {st }}$ every year 2005 through 2013.

\section{Ethics}

Ethical permission was retrieved from the Swedish Ethical Review Authority, reference number 2013/105-31/2, 2014/1041-32, 2017/611-32. No patients were asked for permission to participate and no personal identifications were retrieved. All data is used on population basis to minimize the intrusion of integrity.

\section{Statistics}

The statistical software used was IBM SPSS Statistics, version 23 and 25 for Windows. Continuous variables were presented as means. Proportions were presented as percentages and were compared with $\mathrm{Chi}^{2}{ }^{2}$ test. Annual incidence was calculated as the number of fracture events divided by the population at risk and presented as incidence per 10000 person years. Incidences were calculated for the entire study population and separately for each age category. Fishers test were used to calculate confidence intervals (C.I) for incidence rates. A Poisson regression model adjusting for age group, gender and population at risk was performed, and results are presented as crude and adjusted measures, with a 95\% C.I and according $\mathrm{p}$-value.

\section{Results}

A total number of 90970 distal radius fractures in patients aged 0 to $<18$ years in Sweden were registered during the study period. The mean age at the time for fracture was 10 years (males: 10.73, females 9.33) years and the median 11 (males: 11, females:10) years.

The proportion of male patients in the total population was $60.3 \%$. The distribution between genders was equal in age groups $0-10$ years, but the proportion of male patients was higher in patients $11-17$ years $(\mathrm{p}<0.001)$.

The incidence rate over the whole time period was 52.9/10 000 person years. Male patients aged 11-14 had the highest incidence rate (113-133/10 000 person years). Females fifteen years or older had the lowest incidence rate followed by children $0-6$ years (Table 1 ). The incidence rate differed between age groups and gender during all the studied years (Fig 1) 
74.7) fracture/ 10000 person years (figure 2 and 3). The lowest incidence was found during December at 32,1/10 000 person years (95\% C.I 31.2-33.1).

The incidence as investigated in a Poisson regression model was lower each year $2008-2013$ as compared to $2005(\mathrm{p}<0.001)$ (Table 2$)$.

Table 1: The incidence rates of a distal radius fracture in Sweden during 2005 - 2013 according to registrations in the Swedish Patient Registry presented as incidence rate per 10000 person years per year and age group. 95\% Confidence intervals from fisher's exact test.

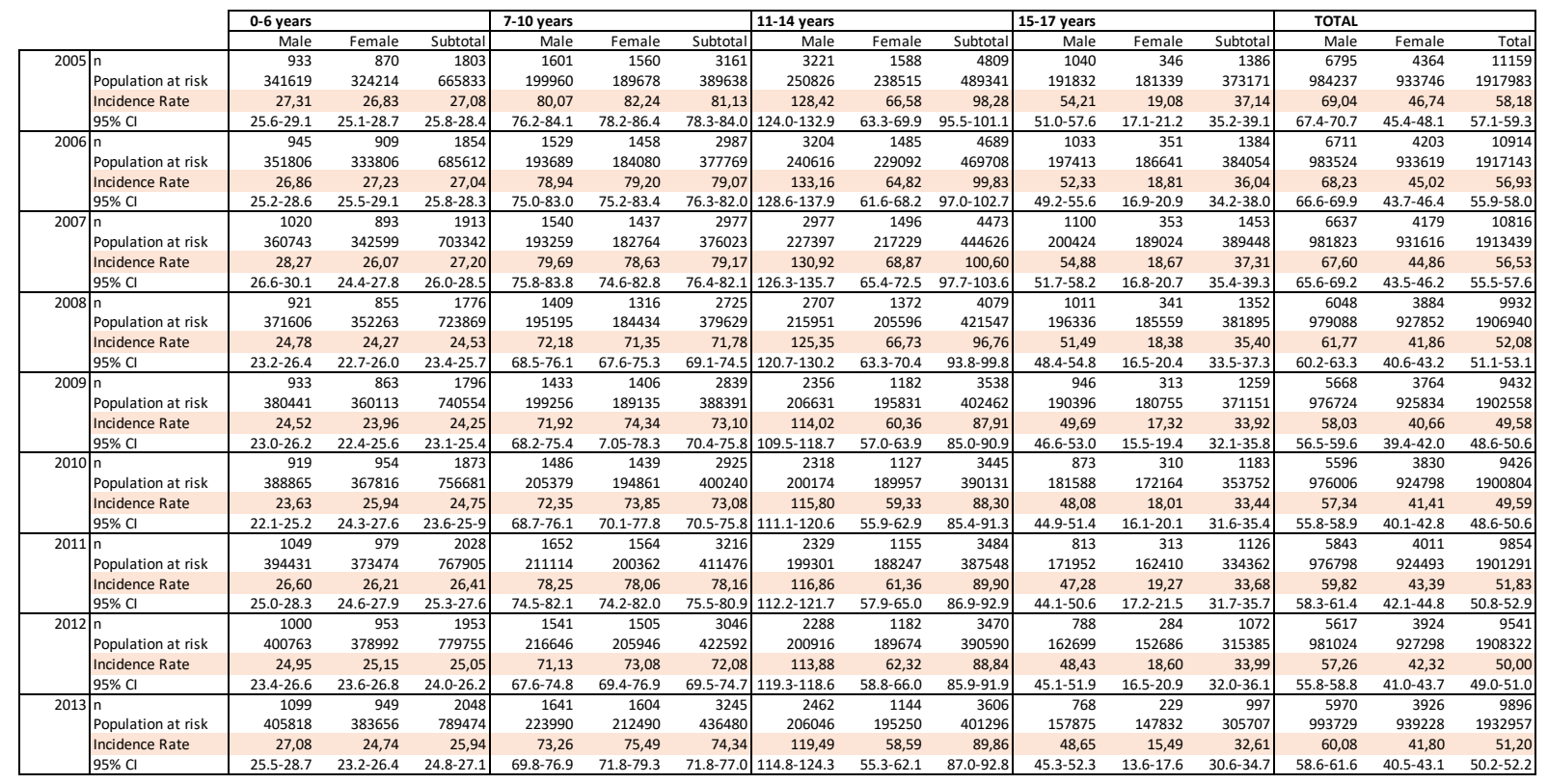

Fig 1: The incidence rates of a distal radius fracture per 10000 person years in Sweden during 2005 - 2013 according to registrations in the Swedish Patient Registry, presented per age group and gender. Error bars indicating the 95\% Confidence Interval.
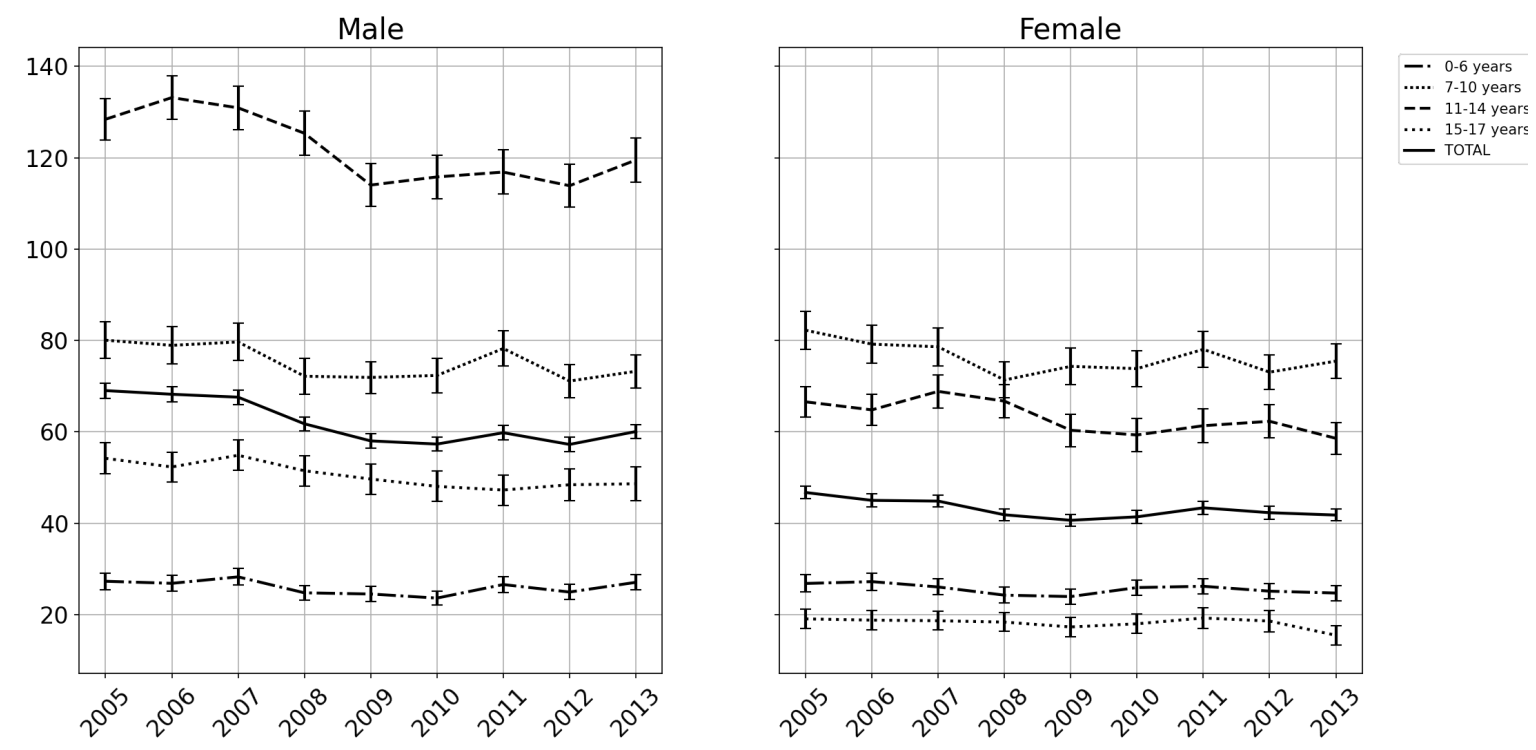

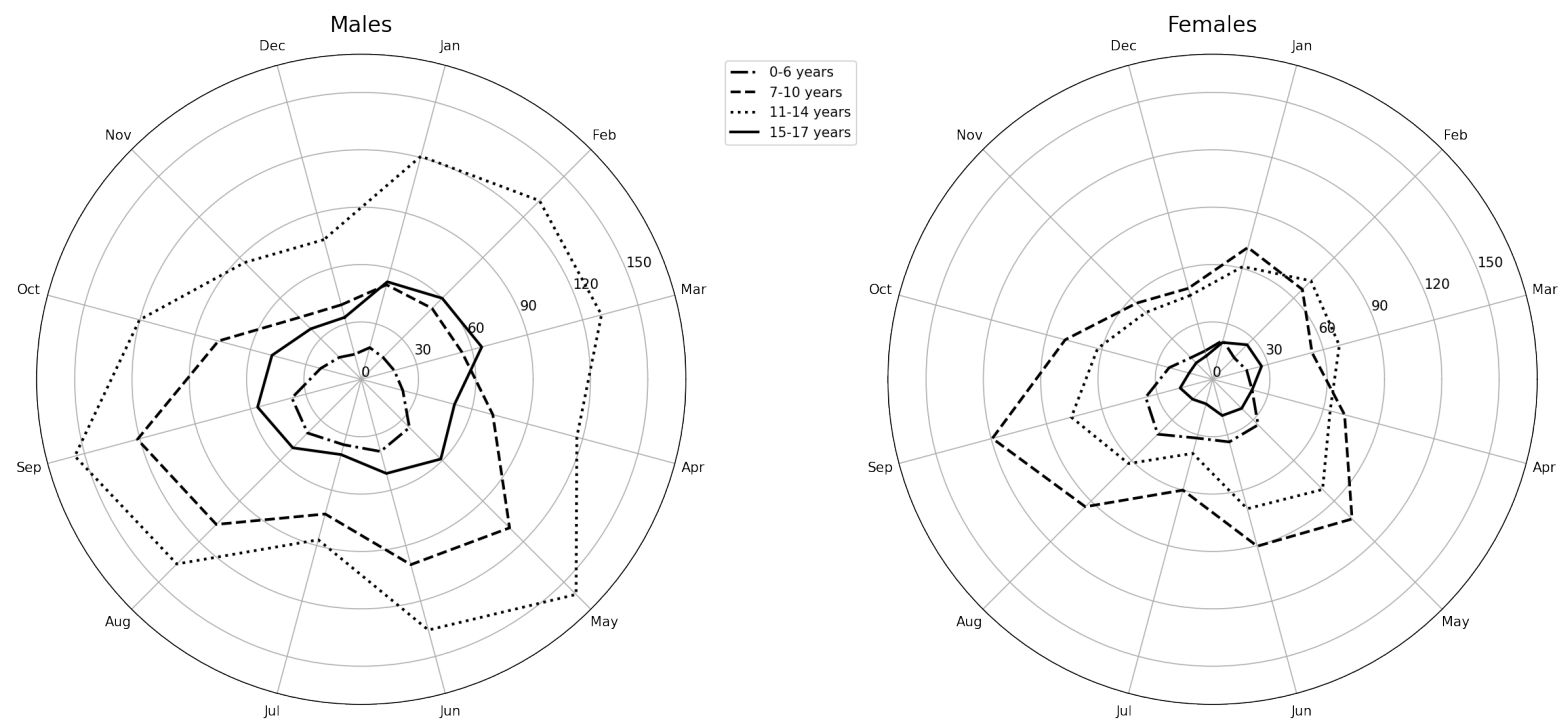

Fig 2: Seasonal variation of incidence rates of a distal radius fracture in different age groups in a polar plot, according to data from the Swedish Patient Registry. Incidence rate is shown per 10000 person years 2005-2013.
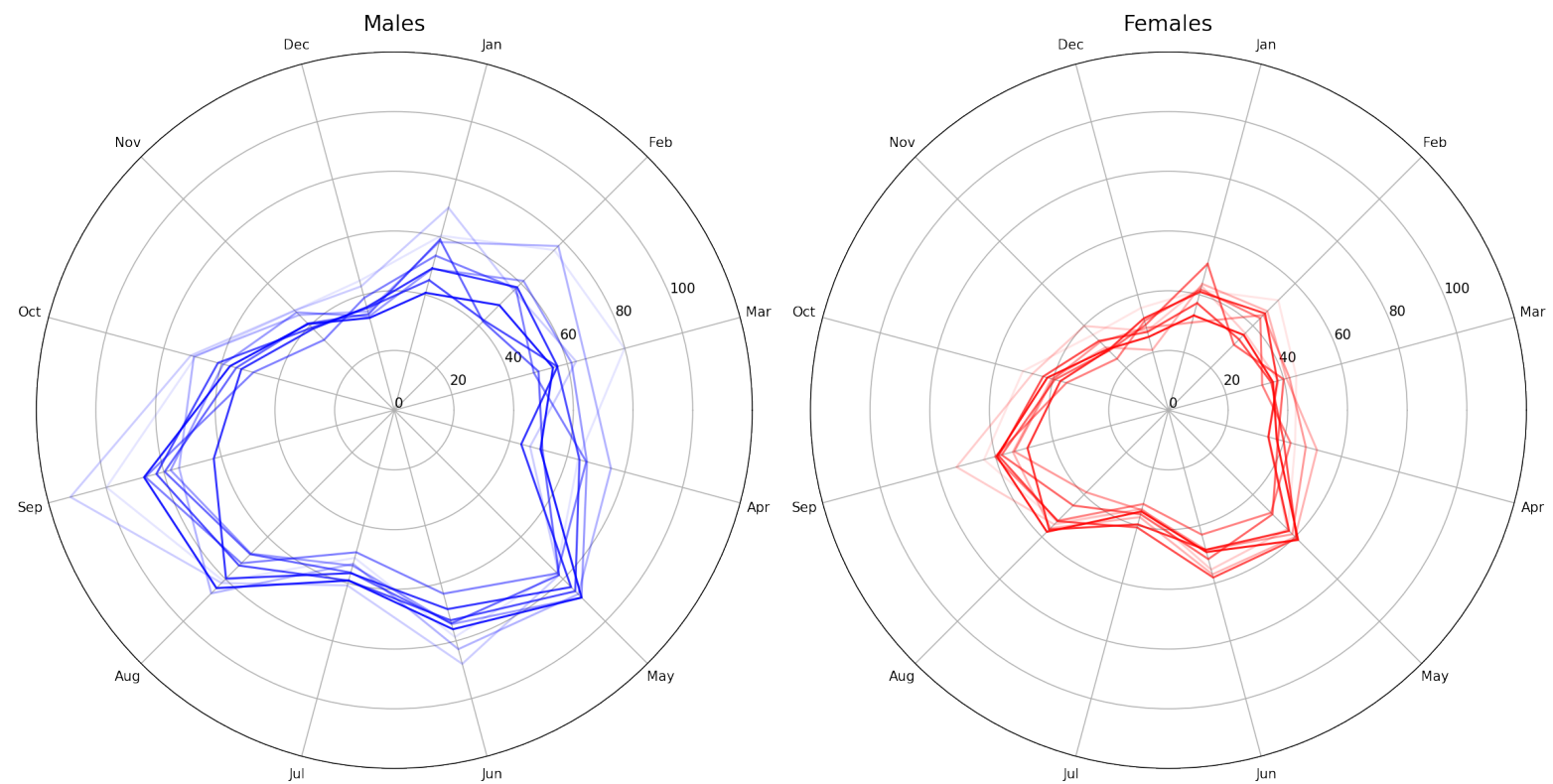

Fig 3: Incidence rates of a distal radius fracture per 10000 person years over the study period according to data from the Swedish Patient Registry. A polar plot is presented for both genders with one line for each year. Opacity in the lines increases from 2005 to 2013. 


\begin{tabular}{|c|c|c|c|c|c|c|c|c|}
\hline & & \multirow[b]{2}{*}{$\begin{array}{c}\begin{array}{c}\text { Population at } \\
\text { risk }\end{array} \\
\end{array}$} & \multirow[b]{2}{*}{$\begin{array}{c}\text { Number of } \\
\text { fractures }\end{array}$} & \multirow[b]{2}{*}{$\begin{array}{c}\text { Incidence rate } \\
\text { per } \mathbf{1 0 . 0 0 0}\end{array}$} & \multicolumn{2}{|c|}{ Univariable } & \multicolumn{2}{|c|}{ Multivariable Adjusted for } \\
\hline & & & & & RR & 95\% CI (p-value) & RR & 95\% CI (p-value) \\
\hline \multirow[t]{9}{*}{ Year } & 2005 & 1917983 & 11159 & 58,2 & Reference & & Reference & \\
\hline & 2006 & 1917143 & 10914 & 56,9 & 0.978 & $\begin{array}{c}0.953-1.004 \\
(0.099)\end{array}$ & 0.993 & $\begin{array}{c}0.967-1.019 \\
(0.592)\end{array}$ \\
\hline & 2007 & 1913439 & 10816 & 56,5 & 0.969 & $\begin{array}{c}0.944-0.995 \\
(0.021)\end{array}$ & 0.999 & $\begin{array}{c}0.972-1.026 \\
(0.917)\end{array}$ \\
\hline & 2008 & 1906940 & 9932 & 52,1 & 0.890 & $\begin{array}{c}0.866-0.914 \\
(<0.001)\end{array}$ & 0.927 & $\begin{array}{c}0.902-0.953 \\
(<0.001)\end{array}$ \\
\hline & 2009 & 1902558 & 9432 & 49,6 & 0.845 & $\begin{array}{c}0.822-0.869 \\
(<0.001)\end{array}$ & 0.886 & $\begin{array}{c}0.862-0.911 \\
(<0.001)\end{array}$ \\
\hline & 2010 & 1900804 & 9426 & 49,6 & 0.845 & $\begin{array}{c}0.822-0.868 \\
(<0.001)\end{array}$ & 0.886 & $\begin{array}{c}0.861-0.911 \\
(<0.001)\end{array}$ \\
\hline & 2011 & 1901291 & 9854 & 51,8 & 0.883 & $\begin{array}{c}0.859-0.907 \\
(<0.001)\end{array}$ & 0.921 & $\begin{array}{c}0.896-0.947 \\
(<0.001)\end{array}$ \\
\hline & 2012 & 1908322 & 9541 & 50,0 & 0.855 & $\begin{array}{c}0.832-0.879 \\
(<0.001)\end{array}$ & 0.883 & $\begin{array}{c}0.859-0.908 \\
(<0.001)\end{array}$ \\
\hline & 2013 & 1932957 & 9896 & 51,2 & 0.887 & $\begin{array}{c}0.863-0.911 \\
(<0.001)\end{array}$ & 0.899 & $\begin{array}{c}0.874-0.923 \\
(<0.001)\end{array}$ \\
\hline \multirow[t]{2}{*}{ Gender } & Female & 8368484 & 49107 & 58,7 & Reference & & Reference & \\
\hline & Male & 8832953 & 74835 & 84,7 & 1.521 & $\begin{array}{c}1.501-1.541 \\
(<0.001)\end{array}$ & 1.445 & $\begin{array}{c}1.425-1.466 \\
(<0.001)\end{array}$ \\
\hline \multirow[t]{4}{*}{ Age } & $\overline{0-6 y}$ & 6592498 & 22434 & 34,0 & Reference & & Reference & \\
\hline & $7-10 y$ & 3578632 & 37429 & 104,6 & 1.591 & $\begin{array}{c}1.561-1.622 \\
(<0.001)\end{array}$ & 3.193 & $\begin{array}{c}2.971-3.432 \\
(<0.001)\end{array}$ \\
\hline & $11-14 y$ & 3820328 & 49408 & 129,3 & 2.088 & $\begin{array}{c}2.051-2.127 \\
(<0.001)\end{array}$ & 3.963 & $\begin{array}{c}3.708-4.235 \\
\quad(<0.001)\end{array}$ \\
\hline & $15-17 y$ & 3216478 & 14671 & 45,6 & 0.658 & $\begin{array}{c}0.642-0.674 \\
(<0.001) \\
\end{array}$ & 1.432 & $\begin{array}{c}1.320-1.552 \\
(<0.001)\end{array}$ \\
\hline
\end{tabular}

Table 2: The incidence rate of a distal radius fracture in Sweden during 2005 - 2013 according to registrations in the Swedish Patient Registry. A Poisson regression model illustrates the development of fracture incidence expressed as a relative risk (RR) adjusted for age and gender.

\section{Discussion}

This observational cohort study analyzing Swedish nationwide registry data describes the gender and age distribution as well as incidence rates of distal radius fractures during the period $2005-2013$.

Our results confirm the findings of previous authors that distal radius fractures are more common in boys than in girls ${ }^{15}$. However, the incidence rates encountered in our data differed somewhat from that previously presented. In a study from a United Kingdom setting, the incidences were lower than in our study population. Exact comparisons are difficult since we have presented our study populations in different age groups. Differences in fracture incidence between countries may be explained by different cultures, with different playing habits, preventive measures and upbringing conditions ${ }^{2}$. Biological differences may also be present, as is the case in an elderly population where the Scandinavian population is known to be more prone to osteoporotic fractures ${ }^{19}$, and hence subject to a high incidence of distal radius fractures. To the best of our knowledge, there is no such differences in predisposing biological factors in the growing skeleton.

In a Dutch study, the incidence rates in the corresponding age groups were approximately similar to our findings ${ }^{13}$. The incidence of distal radius fractures was shown to increase from 
1997 - 2007. In contrast, our data suggest a decrease in incidence rates over our study period. We speculate that an extended study period of the Dutch material may reveal a similar slowdown or decrease in fracture incidence that we found.

Jerrhag et al also present data of an increasing incidence 1999 - 2010 in a southern Swedish region. They have presented their results as mean annual change, thus not making it possible to discern a possible change in increase at the end of their study period ${ }^{20}$.

In nationwide study from South Korea 2005 - 2009, Park et al found a higher incidence rate than ours of 80/10 000 person years. In agreement with our study findings, they report a decreasing trend in the late part of the study period. ${ }^{21}$

In Germany Körner et al studied the change in pediatric upper extremity fractures 2002 2017 and reported only a slight change in incidence rate during the study period. ${ }^{22}$

There is data that supports that physical and mental wellbeing in children is associated with physical activity ${ }^{12,23}$. The association between physical activity and occurrence of fractures however is debated: In a study from the United Kingdom, Clark et al. (2008) suggested a positive association between a high level of physical activity and fracture risk in children ${ }^{24}$. In a Swedish population there was no increase in fracture risk in a long-term moderate exercise intervention program among schoolchildren ${ }^{25}$. The influence of physical exercise on fracture risk may act as a protective factor, if one believes that physical activity strengthens the bone structure and improves balance and coordination. It may also counteract childhood obesity and overweight that have been described to be associated with an increased risk of forearm fractures. ${ }^{26,27}$. However, there is reason to believe that exposure to bicycling, tree climbing, monkey bars and trampolines would produce more fractures than computer games or similar digital entertainment. We therefore speculate that the decrease in incidence that we discern in our material may represent a change in injury patterns secondary to life-style changes in children. What long term effect this may have on children's health and future risk for pathology is yet to be investigated.

Some limitations to this study are admitted. First and foremost, this is a registry study on a population level meaning that details at the individual level are not available. The results rely on the ICD-10-SE code of diagnosis registrations and no details on fracture type, fracture pattern or coinciding observations can be obtained or analyzed. The registry design, on the other hand, offers a nationwide and large study population during a long time providing a great amount of fracture data. The age groups were constructed to separate different populations with different activity patterns. The cut off of different age groups could have been set differently.

\section{Conclusion}

The incidence of distal radius fractures in the Swedish population $0-17$ years of age was lower in 2008 - 2013 as compared to 2005. Further studies are necessary to reveal if the incidence will continue to decrease. The incidence of distal radius fractures was higher among male than in female patients. There are seasonal variations in distal radius incidences with different patterns in different age groups.

\section{List of abbreviations}

C.I: confidence intervals 
ICD-10-SE: Swedish version of the International statistical classification of diseases and related health problems $10^{\text {th }}$ revision

NPR: The Swedish National Patient Register

\section{Declarations}

Ethics approval and consent to participate

Ethical permission was retrieved from the Swedish Ethical Review Authority, reference number 2013/105-31/2, 2014/1041-32, 2017/611-32. According to the permission the study could be undertaken without personal consent. All data is used on population basis to minimize the intrusion of integrity, no personal identifications were retrieved. The study was performed according to the Helsinki declaration.

Consent for publication

Not applicable, no personal information is included in the material.

Availability of data and materials

The material could be retrieved from the corresponding author upon reasonable request

Competing interests

The authors have no competing interests

Funding

No funding

Authors' contributions

HS and CMN: study design, data analysis and writing the manuscript.

Acknowledgements

The Auther wish to thank Hans Pettersson for his contributions and advices.

\section{References}

1. Jones IE, Williams SM, Dow N, Goulding A. How many children remain fracture-free during growth? a longitudinal study of children and adolescents participating in the Dunedin Multidisciplinary Health and Development Study. Osteoporosis international : a journal established as result of cooperation between the European Foundation for Osteoporosis and the National Osteoporosis Foundation of the USA. 2002;13(12):990-5.

$2 . \quad$ Landin LA. Epidemiology of children's fractures. Journal of pediatric orthopedics Part B. 1997;6(2):79-83.

3. Hedström EM, Svensson 0, Bergström U, Michno P. Epidemiology of fractures in children and adolescents. Acta orthopaedica. 2010;81(1):148-53.

4. Cooper C, Dennison EM, Leufkens HG, Bishop N, van Staa TP. Epidemiology of childhood fractures in Britain: a study using the general practice research database. J Bone Miner Res. 2004;19(12):1976-81.

5. $\quad$ Rodríguez-Merchán EC. Pediatric fractures of the forearm. Clinical orthopaedics and related research. 2005(432):65-72. 
6. $\quad$ Ryan LM, Teach SJ, Searcy K, Singer SA, Wood R, Wright JL, et al.

Epidemiology of pediatric forearm fractures in Washington, DC. The Journal of trauma. 2010;69(4 Suppl):S200-5.

7. Magarey AM, Boulton TJ, Chatterton BE, Schultz C, Nordin BE, Cockington RA. Bone growth from 11 to 17 years: relationship to growth, gender and changes with pubertal status including timing of menarche. Acta paediatrica (Oslo, Norway : 1992). 1999;88(2):139-46.

8. $\quad$ Mayranpaa MK, Makitie 0, Kallio PE. Decreasing incidence and changing pattern of childhood fractures: A population-based study. J Bone Miner Res. 2010;25(12):2752-9.

9. Mellstrand-Navarro C, Pettersson HJ, Tornqvist H, Ponzer S. The operative treatment of fractures of the distal radius is increasing: results from a nationwide Swedish study. The bone \& joint journal. 2014;96-b(7):963-9.

10. Handoll HH, Elliott J, Iheozor-Ejiofor Z, Hunter J, Karantana A. Interventions for treating wrist fractures in children. Cochrane database of systematic reviews (Online). 2018;12(12):Cd012470.

11. Pannu GS, Herman M. Distal radius-ulna fractures in children. The Orthopedic clinics of North America. 2015;46(2):235-48.

12. Elinder LS, Heinemans N, Zeebari Z, Patterson E. Longitudinal changes in health behaviours and body weight among Swedish school children--associations with age, gender and parental education--the SCIP school cohort. BMC Public Health. 2014;14:640.

13. de Putter CE, van Beeck EF, Looman CW, Toet H, Hovius SE, Selles RW. Trends in wrist fractures in children and adolescents, 1997-2009. The Journal of hand surgery. 2011;36(11):1810-5.e2.

14. Khosla S, Melton LJ, 3rd, Dekutoski MB, Achenbach SJ, Oberg AL, Riggs BL. Incidence of childhood distal forearm fractures over 30 years: a population-based study. Jama. 2003;290(11):1479-85.

15. Mamoowala N, Johnson NA, Dias JJ. Trends in paediatric distal radius fractures: an eight-year review from a large UK trauma unit. Ann R Coll Surg Engl. 2019;101(4):297-303.

16. Socialstyrelsen [Available from: https://www.socialstyrelsen.se/en/. 17. Ludvigsson JF, Andersson E, Ekbom A, Feychting M, Kim JL, Reuterwall C, et al. External review and validation of the Swedish national inpatient register. BMC Public Health. 2011;11:450.

18. Statistics Sweden 2018 [Available from:

http://www.statistikdatabasen.scb.se/pxweb/en/ssd/.

19. Kanis JA, Odén A, McCloskey EV, Johansson H, Wahl DA, Cooper C. A systematic review of hip fracture incidence and probability of fracture worldwide. Osteoporosis international : a journal established as result of cooperation between the European Foundation for Osteoporosis and the National Osteoporosis Foundation of the USA. 2012;23(9):2239-56.

20. Jerrhag D, Englund M, Petersson I, Lempesis V, Landin L, Karlsson MK, et al. Increasing wrist fracture rates in children may have major implications for future adult fracture burden. Acta orthopaedica. 2016;87(3):296-300.

21. Park MS, Chung CY, Choi IH, Kim TW, Sung KH, Lee SY, et al. Incidence patterns of pediatric and adolescent orthopaedic fractures according to age groups and seasons in South Korea: a population-based study. Clin Orthop Surg. 2013;5(3):161-6. 
22. Körner D, Gonser CE, Bahrs C, Hemmann P. Change in paediatric upper extremity fracture incidences in German hospitals from 2002 to 2017: an epidemiological study. Archives of orthopaedic and trauma surgery. 2020;140(7):88794.

23. Janssen I, Leblanc AG. Systematic review of the health benefits of physical activity and fitness in school-aged children and youth. Int J Behav Nutr Phys Act. 2010;7:40.

24. Clark EM, Ness AR, Tobias JH. Vigorous physical activity increases fracture risk in children irrespective of bone mass: a prospective study of the independent risk factors for fractures in healthy children. J Bone Miner Res. 2008;23(7):1012-22.

25. Detter FT, Rosengren BE, Dencker M, Nilsson J, Karlsson MK. A 5-year exercise program in pre- and peripubertal children improves bone mass and bone size without affecting fracture risk. Calcified tissue international. 2013;92(4):385-93.

26. Moon RJ, Lim A, Farmer M, Segaran A, Clarke NM, Dennison EM, et al. Differences in childhood adiposity influence upper limb fracture site. Bone. 2015;79:8893.

27. Manning Ryan L, Teach SJ, Searcy K, Singer SA, Wood R, Wright JL, et al. The Association Between Weight Status and Pediatric Forearm Fractures Resulting From Ground-Level Falls. Pediatric emergency care. 2015;31(12):835-8. 
Figures
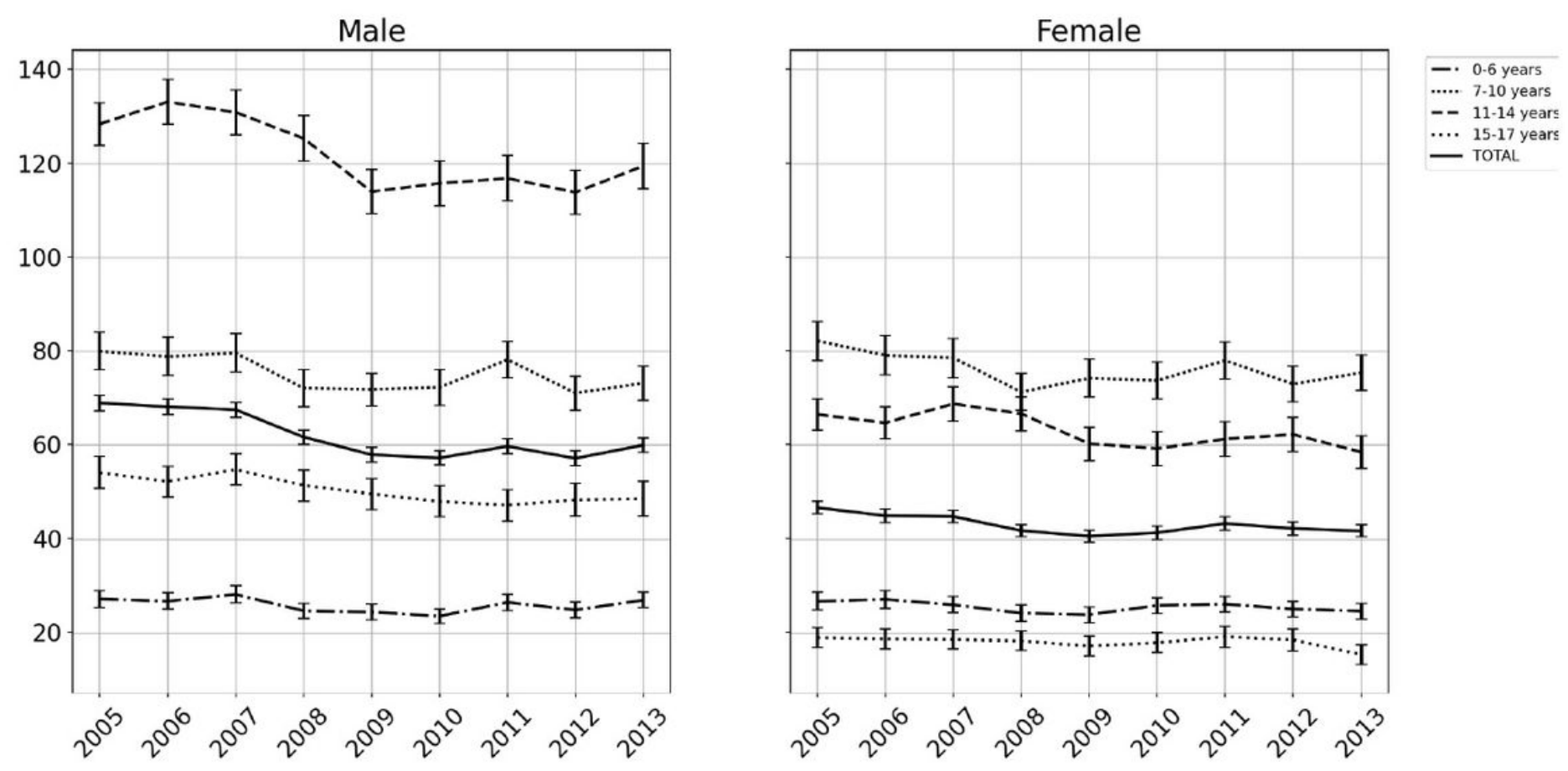

\section{Figure 1}

The incidence rates of a distal radius fracture per 10000 person years in Sweden during 2005 - 2013 according to registrations in the Swedish Patient Registry, presented per age group and gender. Error bars indicating the $95 \%$ Confidence Interval.
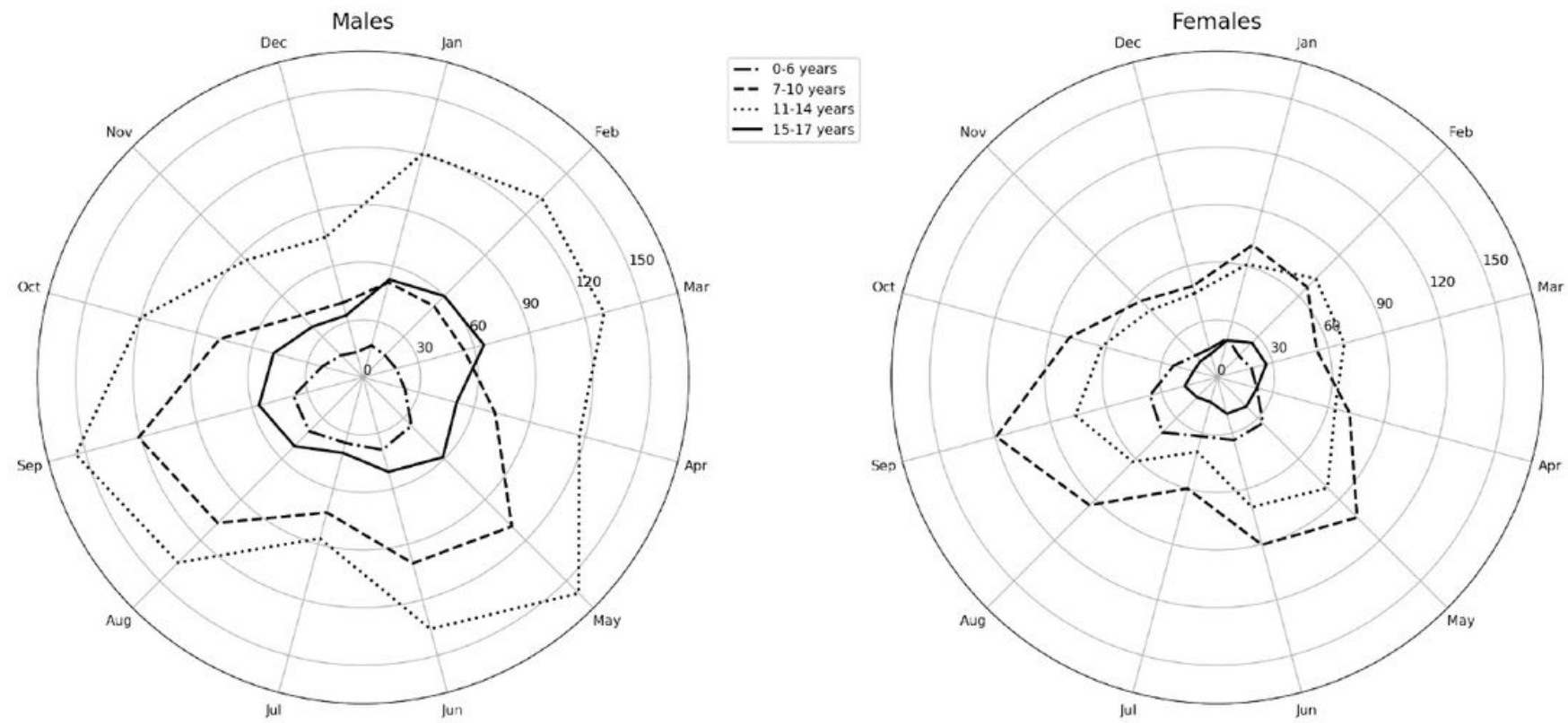

Figure 2 
Seasonal variation of incidence rates of a distal radius fracture in different age groups in a polar plot, according to data from the Swedish Patient Registry. Incidence rate is shown per 10000 person years 2005-2013.
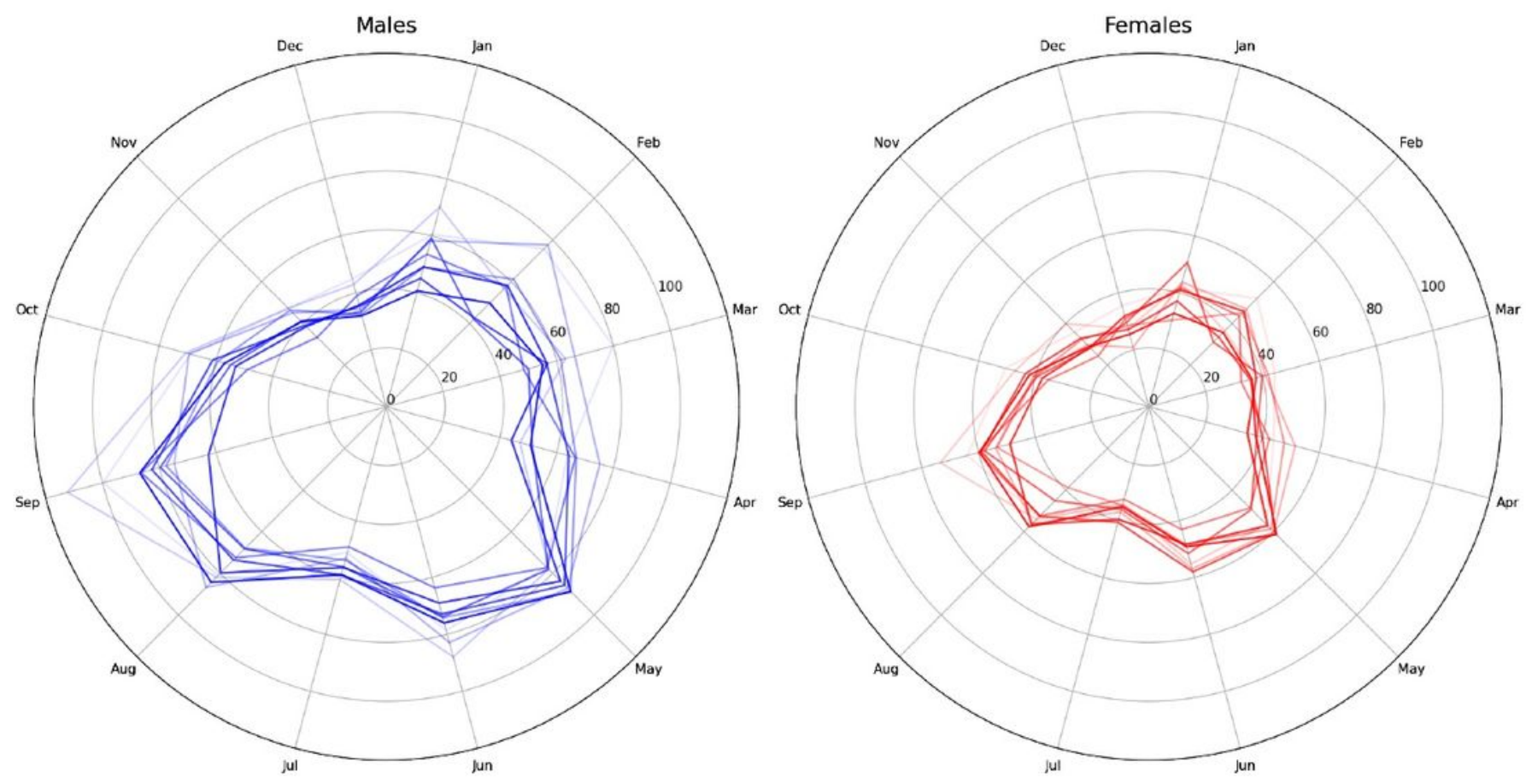

Figure 3

Incidence rates of a distal radius fracture per 10000 person years over the study period according to data from the Swedish Patient Registry. A polar plot is presented for both genders with one line for each year. Opacity in the lines increases from 2005 to 2013. 